\title{
Open Access Journals are like a Box of Chocolates
}

\section{Ekant Veer}

Department of Marketing, University of Canterbury, New Zealand

\section{Editorial}

You never know what you're going to get. It's the truth and, unfortunately, it's a truth that every Open Access journal in every field will need to overcome in the next five years if the Open Access model is to gain legitimacy as a means of disseminating knowledge. Offering knowledge in a free and open manner is wonderful. Everyone likes a free gift. However, if the gift you receive, even if it is free, is of little use or relevance to you, then the free gift is valueless. In the same way, if the knowledge disseminated through Open Access journal is irrelevant, lacking rigour, tautological, and/or meaningless, then the journal, even though it offers its knowledge for free, becomes valueless. In this brief editorial I discuss some of the necessary steps Open Access journals will need to take in order to gain legitimacy as a means of disseminating knowledge and overcome some of the perceptions that currently burden Open Access journals.

\section{Avoid becoming a graveyard}

Open Access, whether we like it or not, does not have a strong reputation. There exists a perception that Open Access journals are a graveyard for poor quality research that cannot be published under the traditional publication model. In a model where authors pay to have their articles published and journal editors are rewarded for each article that is published, there exists the perception that profiteering occurs by publishing sub-standard manuscripts in order to generate funds. However false this perception may be, it still exists. Avoiding becoming a graveyard for poor quality research is fundamental to improving the relevance and impact of an Open Access journal.

Unfortunately, a few poor quality articles can lead to a reinforcement effect of this perception [1,2], even though traditional journals may also publish articles of varying quality. Expectation biases [3] may even lead to some authors seeking out poorer quality journals in an attempt to extend vitriol against Open Access. Whatever the risks and misperceptions, Open Access must succeed in order to ensure that knowledge is accessed by as many persons as possible.

The European Commission recently announced that any projects funded by their Horizon 2020 fund must make publications coming from the research freely available to all [4]. Harvard University announced last year that they will be encouraging all of their professors to target Open Access journals, rather than traditional journals [5]. The tide is turning towards Open Access, but this is not to say that all Open Access journals will be treated equally. The contents of the journal must still make a contribution to our knowledge. It does not matter whether it is a contribution and impact on theories that guide academic business research; on methods used to conduct business research, or on business practice, a contribution must be made in every article.

\section{Becoming high-impact Open Access}

Overcoming the misperceptions and misconceptions of Open Access will be an uphill battle. There will be many who will remain loyal to the traditional model, but there will be others who will be willing to forge a path that will benefit Open Access journals and all those in need of more access to cutting edge research. There are many strategies that can be employed to secure the success of Open Access journals - the following are simply my thoughts on how an Open Access journal is able to maintain both its impact and freedom:

1) Never be seen to compromise on quality. Rightly or wrongly, Open Access could be perceived as being a means of making profits from authors who are willing to pay to have their articles published. If this misperception is to be eradicated then an Open Access journal cannot be seen to have any conflict of interest between its financial and academic practices. Academic rigor and quality must always come before financial gain. Strict review processes and high quality standards must be maintained to avoid becoming a 'graveyard' of academic research.

2) Have a strong and passionate editorial team that are willing to take risks. The editorial team will not only be the source of policy decisions and reviewers, they will also be the main source of marketing and promotion for a journal. If the editorial team is not passionate and proud of Open Access, it would be difficult for others to become similarly passionate and proud of an Open Access journal. The editorial team and encourage colleagues to submit articles, but also be quality control barriers to ensure the journal's integrity is constantly maintained.

3) Secure invited articles from the most respected authors in the field. The misperception that Open Access journals are a home for poor quality articles can be overcome with some well-targeted and poignant essays from respected academics and practitioners. Having articles from respected authors can draw attention to the journal and can encourage others to consider the journal for their own work. More importantly, rightly or wrongly, an article written by a well-known author can drive citations, which drives exposure, which drives knowledge of the journal and other articles published within it.

4) Push the boundaries of knowledge. If readers read a journal because of a famous author or editorial team, they are unlikely to continue to read unless the journal is able to offer something more than one or two star players. There needs to be a consistent quality and intrigue that keeps readers and authors clambering back for more. By pushing the boundaries of knowledge and offering revolutionary, not just evolutionary, shifts in our knowledge should be encouraged. Take risks. Drive knowledge, rather than be dictated by what is known. Strive for work that challenges the norms and creates the future, rather than confirms the past and offers no advancement of any real value.

*Corresponding author: Ekant Veer, Department of Marketing, University of Canterbury, New Zealand, Tel: 64-3-364-2987; E-mail: ekant.veer@canterbury.ac.nz

Received August 16, 2012; Accepted August 18, 2012; Published August 23, 2012

Citation: Veer E (2012) Open Access Journals are like a Box of Chocolates. J Bus \& Fin Aff 1:e115. doi:10.4172/2167-0234.1000e115

Copyright: (c) 2012 Veer E. This is an open-access article distributed under the terms of the Creative Commons Attribution License, which permits unrestricted use, distribution, and reproduction in any medium, provided the original author and source are credited. 
5) Be worthwhile. Finally, and most importantly, express the contribution of one's research overtly. Make the research published meaningful and useful to the target audience. Ensure any research published is not only academically rigorous, but also meaningful for its readers. Always add value to one's field.

As I mentioned previously, Open Access is a precarious journal format and a few misguided preconceptions can destroy an Open Access journal's reputation. However, slowly and carefully building a reputation of excellence will ensure that it does not become a box of chocolates, but a known quantity; a meaningful source of knowledge, and a more accessible form of knowledge dissemination for a wider audience.

\section{References}

1. Davison M (1983) Bias and sensitivity to reinforcement in a concurrent-chain schedule. J Exp Anal Behav 40: 15-34.

2. Nevin JA (1988) Behavioral momentum and the partial reinforcement effect Psychological Bulletin 103: 44-56.

3. Ross L, Greene D, House P (1977) The "false consensus effect": An egocentric bias in social perception and attribution processes. J Exp Soc Psychol 13: 279 301

4. http://www.timeshighereducation.co.uk/story.asp?sectioncode=26\&storycode= $420689 \& \mathrm{c}=1$

5. http://osc.hul.harvard.edu/policies 